\section{Ideias em disputa sobre as atribuições do Estado na prevenção e controle da obesidade infantil no Brasil}

\author{
Competing ideas on the State's roles in the \\ prevention and control of childhood \\ obesity in Brazil
}

Ideas en disputa sobre las atribuciones del Estado en la prevención y control de la obesidad infantil en Brasil

\section{Resumo}

O estudo analisou as ideias em disputa em torno das atribuições do Estado na prevenção e controle da obesidade infantil no Brasil com base no referencial de análise cognitiva de políticas públicas. Realizou-se análise documental e entrevista semiestruturada com 20 depoentes referenciados às esferas do Estado/ Governo, sociedade civil organizada e do setor privado comercial. O Estado foi considerado o principal responsável pelo enfrentamento da obesidade infantil, mas as concepções sobre suas atribuições variaram de acordo com as narrativas sobre os condicionantes da obesidade e as soluções apresentadas. O setor privado comercial critica o Estado regulador em nome da liberdade de decisão dos pais. Representantes da sociedade civil e de parte do governo valorizam ações regulatórias e reconhecem que são fundamentais. Consideram que os acordos para a redução de ingredientes, realizados entre o governo e a indústria alimentícia, não são efetivos. Porém, alguns representantes do governo os defendem. Essas tensões e contradições também se expressam nos documentos de politicas que reconhecem que as práticas do setor privado comercial favorecem a obesidade, mas o consideram parceiro. Os argumentos contrários ao Estado regulador são pautados nos condicionantes individuais da obesidade, contudo, as práticas institucionais do setor privado comercial é que são objeto de regulação e não o comportamento dos indivíduos. No entanto, esse tipo de argumento é parte da ação politica corporativa, pois omite os conflitos de interesses que vêm contribuindo para retardar a redução da prevalência da obesidade.

Obesidade Infantil; Programas e Políticas de Nutrição e Alimentação; Controle da Obesidade; Estado
Patricia Henriques 1

Luciene Burlandy 1

Patricia Camacho Dias 1

Gisele O'Dwyer ${ }^{2}$

doi: 10.1590/0102-311X00016920

\author{
Correspondência \\ $P$. Henriques \\ Universidade Federal Fluminense. \\ Rua Mário Santos Braga 30, Campus do Valonguinho, Niterói, \\ RJ 24020-140, Brasil. \\ patihenriques@gmail.com \\ 1 Universidade Federal Fluminense, Niterói, Brasil. \\ 2 Escola Nacional de Saúde Pública Sergio Arouca, Fundação \\ Oswaldo Cruz, Rio de Janeiro, Brasil.
}




\section{Introdução}

Importantes conquistas nas políticas públicas repercutiram significativamente no acesso à alimentação nos últimos anos no Brasil. Contudo, dados demonstram que 54\% dos adultos 1 e 33,5\% das crianças sofrem com excesso de peso e obesidade 2. O consumo insuficiente de frutas e verduras e o aumento do consumo de ultraprocessados 3 , somados ao baixo perfil de atividade física, contribuem para a crescente prevalência de excesso de peso e obesidade e da incidência de doenças crônicas não transmissíveis (DCNT) 4.

A substituição de alimentos naturais ou pouco processados por ultraprocessados é uma tendência internacional, inclusive porque a indústria de alimentos opera transnacionalmente. A ação política corporativa desse setor impulsiona esse perfil de consumo ao adotar estratégias semelhantes para influenciar os processos decisórios dos governos nacionais 5,6,7.

O governo brasileiro propôs um conjunto de ações para a Promoção da Alimentação Adequada e Saudável (PAAS), com reflexos potenciais no enfrentamento da obesidade infantil 8 , formalizadas nos documentos da Política Nacional de Segurança Alimentar e Nutricional (PNSAN) 9, da Política Nacional de Alimentação e Nutrição (PNAN) 10 e da Política Nacional de Promoção da Saúde 11, além dos Guias Alimentares para a População 12 e para as crianças menores de dois anos 13, e do Marco de Referência de Educação Alimentar e Nutricional 14. No entanto, o ritmo de implementação é descompassado, pois afeta de forma distinta os interesses dos atores envolvidos 15,16. Esse processo é condicionado pelas ideias em disputa sobre as atribuições do Estado e dos governos, e sobre os limites de intervenção estatal na vida privada 17 e nos setores econômicos, especialmente na regulação das práticas produtivas e comerciais da indústria 18 .

Os argumentos que balizam a defesa de que uma determinada ação é estratégica para a PAAS estão associados a "soluções" que atendem a determinados interesses e que abarcam desde ações estatais normativas, coercitivas, impositivas, regulatórias ou estratégias mais pactuadas em uma perspectiva de um Estado menos interventor 19. Conformam-se diferentes ideias sobre o quanto o Estado e os governos devem intervir ou não na esfera privada, como devem e em quais questões. Controvérsias sobre esses temas são históricas e centrais na análise de políticas públicas e atravessam o pensamento acadêmico no campo da ciência política há algumas décadas 20 .

Considerando-se a relevância desse debate, o objetivo do estudo foi analisar as ideias em disputa em torno das atribuições do Estado (o que deve ser feito e quais os limites de atuação na esfera privada) no âmbito das políticas de alimentação e nutrição voltadas para a prevenção e o controle da obesidade infantil no Brasil, especialmente no que se refere à PAAS.

\section{Metodologia}

O estudo foi pautado na abordagem cognitiva de análise de políticas que considera que as ideias que mobilizam o processo político são dinâmicas e condicionadas pelas instituições e interesses em disputa 21,22. As ideias foram concebidas como esquemas de interpretação compartilhados pelos agentes sociais, estruturas de sentido que estabelecem como os problemas públicos e as "soluções" são percebidos. Focalizou-se as ideias de atores situados em diferentes instituições, dentro e fora do Estado, sobre as atribuições estatais 23 .

Os métodos utilizados foram análise documental e entrevista semiestruturada, elaborada com base em um estudo semelhante que analisou as ideias de atores-chave da cidade de Nova Iorque (Estados Unidos), acerca da importância, da causa e das soluções possíveis para a obesidade infantil 24. Foram entrevistados integrantes dos espaços de participação e controle social da PNAN no âmbito do Sistema Único de Saúde (SUS) e da PNSAN no âmbito do sistema nacional de segurança alimentar e nutricional, sendo que 10 atuam em instituições do estado/governo, nove da sociedade civil organizada e um do setor privado comercial, totalizando 20 depoentes.

Foram analisados os seguintes documentos produzidos nos últimos 15 anos: pelo Estado, as principais políticas e estratégias do Governo Federal 9,10,11,12,25,26,27,28,29; pela sociedade civil organizada, publicações do Conselho Nacional de Segurança Alimentar e Nutricional (CONSEA) 30 e; pelo setor privado comercial, documentos do Conselho Nacional de Autorregulamentação Publicitária 
(CONAR) 31,32. A análise documental contribuiu para mapear os atores, as diferentes conjunturas político institucionais, as ideias e interesses em disputa.

Os dados foram coletados em 2016 e analisados de forma integrada por meio dos conceitos e perguntas centrais do estudo e de análise de conteúdo temática, visando a identificar categorias que emergiram do empírico. As categorias norteadoras da análise foram as ideias e argumentos em disputa em torno das atribuições do Estado nas políticas de alimentação e nutrição, dos tipos de ações propostas e dos modelos de regulação de alimentos.

A pesquisa foi aprovada pelo Comitê de Ética em Pesquisa da Escola Nacional de Saúde Pública Sergio Arouca da Fundação Oswaldo Cruz (Ensp/Fiocruz - CAAE 42879015.0.0000.5240). Antes de iniciar a entrevista foi solicitada a assinatura do Termo de Consentimento Livre e Esclarecido aos participantes.

\section{Resultados}

A ideia prevalente nas narrativas e nos documentos de políticas públicas é que a obesidade é um problema de saúde pública multicausal condicionado, principalmente, por fatores ambientais modificáveis. Os argumentos baseiam-se em estudos epidemiológicos, mas são distintas as ideias sobre seus condicionantes. Os depoentes do Estado e da sociedade civil organizada destacaram o aumento do consumo de alimentos ultraprocessados, o lazer sedentário e a influência da mídia, e o do setor privado comercial ressaltou elementos do comportamento "individualizado", como o sedentarismo e a saída da mulher para o mercado de trabalho.

Para os depoentes da setor privado comercial, um forte condicionante da obesidade infantil é o poder de penetração das indústrias de alimentos ultraprocessados e a capacidade de transformação dos seus produtos e termos publicitários para adequarem-se aos distintos "públicos-alvo", incluindo: a promoção de produtos industrializados em vários ambientes que a criança acessa, como o próprio domicílio e a escola, e a utilização de termos que associem os produtos com práticas saudáveis.

A abordagem da obesidade como questão social foi pouco problematizada pelos depoentes que atuam na área de saúde, ainda que repercuta na discussão sobre as atribuições do Estado. Essa perspectiva foi identificada apenas por um depoente da sociedade civil organizada que atua em questões de educação e agricultura.

\section{Ideias e argumentos em disputa quanto às atribuições do Estado}

Alguns documentos de políticas nacionais sinalizam contradições quanto às estratégias adotadas pelo próprio governo, uma vez que reconhecem que as práticas do setor privado comercial contribuem para o aumento da obesidade, mas sugerem ações que atribuem a este setor o status de "parceiro".

No discurso do setor privado comercial a solução para a epidemia da obesidade infantil passa pela família, pela educação e pela autorregulamentação da publicidade de alimentos exercida pelo CONAR e não pelos mecanismos de regulação estatal. O depoente do setor privado comercial defende o setor publicitário argumentando que "para muitos, a publicidade de alimentos e refrigerantes tornou-se a vilã que precisa ser banida com a maior brevidade possível e sem maiores discussões, como se essa medida fosse capaz de acabar com a obesidade". Ainda como parte da mesma narrativa, o Estado deve "fornecer educação", alimentação escolar, fazer comunicação sobre a alimentação "correta” e estimular o exercício físico.

Contrariamente, a ideia fortemente disseminada pela sociedade civil organizada, e por alguns depoentes do governo, é que o Estado deveria desempenhar um papel regulatório fundamental sobre a ação e a publicidade das indústrias de alimentos ultraprocessados, protegendo a alimentação não só das crianças, mas da população como um todo, por meio de ações que assegurassem alimentação escolar saudável, rotulagem frontal de advertência e tributação de alimentos com alto teor de açúcar. 
Programas e ações propostos pelos diferentes segmentos

\section{- Ações no âmbito da escola}

A escola foi apontada como o espaço mais estratégico para o desenvolvimento de ações de prevenção e controle da obesidade infantil, por possibilitar que as crianças acessem uma alimentação mais saudável e ao mesmo tempo vivenciem atividades favoráveis à saúde e à alimentação adequada. Foi consenso entre todos os depoentes que as atribuições do Estado nesse sentido devem focar em programas no âmbito da escola e em ações de educação alimentar e nutricional. Todavia, as estratégias regulatórias no espaço escolar foram reportadas como importantes apenas pelos atores do Estado e da sociedade civil organizada.

Os documentos governamentais que estabelecem diretrizes de PAAS nas escolas 25,26,27 representam o discurso governamental sobre a proteção da alimentação do escolar. De forma mais contundente, a sociedade civil organizada apregoa que a escola deve ser compreendida como um espaço para a formação de valores e, portanto, não deveria permitir a entrada de empresas comerciais, expondo logos e imagens de marcas que contribuem para consolidar hábitos não saudáveis. Alguns depoentes da sociedade civil organizada argumentam que essas práticas são abusivas e ilegais por desrespeitarem a proteção integral e a vulnerabilidade da criança, considerando a atribuição do Estado de proteger os direitos, princípios e valores socialmente pactuados, pois violam a Constituição Federal de 1988 (http://www.planalto.gov.br/ccivil_03/constituicao/constituicao.htm), o Estatuto da Criança e do Adolescente 33, o Código de Defesa do Consumidor 34 e a Resolução no 163 do Conselho Nacional dos Direitos da Criança e do Adolescente 35.

Além disso, também problematizaram que a garantia de direitos públicos e a redução de desigualdades, inclusive em saúde, fundamentais no contexto brasileiro, dificilmente se realizam sem que o Estado cumpra atribuições específicas que são intransferíveis para outras esferas como a sociedade civil organizada ou o setor privado comercial .

\section{- Ações de educação alimentar e nutricional}

A educação alimentar e nutricional foi reiterada pelos depoentes dos três segmentos como atribuição do Estado. Para além das ações educativas no espaço da escola, a maioria dos entrevistados da sociedade civil organizada e governo citaram o Guia Alimentar para a População Brasileira 12 como potencial para a PAAS, por veicular informações de forma mais acessível e menos prescritiva.

O guia não apareceu nas narrativas do setor privado como um instrumento de educação alimentar e nutricional. Contudo, esse setor argumentou que a principal atribuição estatal é promover "campanhas para alimentação saudável” e que a sua atuação está pautada em atividades educativas e autorregulamentação. Igualmente, documentos do CONAR indicam que o Estado deve educar para "formar consumidores civilizados".

\section{Ações regulatórias}

Foi consenso para os depoentes da sociedade civil organizada que o Estado deve regular a publicidade de alimentos dirigida ao público infantil, atualizar o modelo de rotulagem nutricional e propor medidas fiscais para a taxação de alimentos ultraprocessados. Já os depoentes do Estado não foram unânimes quanto a essas perspectivas, especialmente aqueles situados em cargos de confiança e nos mais altos escalões da hierarquia institucional.

Nessa direção, o argumento de parte da sociedade civil organizada refere-se à falta de comprometimento dos representantes governamentais que em princípio deveriam defender o interesse público. "Existem diferenças de intenções individuais e partidárias sem limites éticos, morais e legais que corrompem o objetivo maior do Estado".

Um depoente do governo argumentou que a política pública é importante, mas que é necessário que o cidadão participe e que esteja consciente. Para ele há complexidades, mas existem soluções possíveis que dependem do trabalho do Governo Federal em parceria com municípios, estados e sociedade civil. Argumenta que é preciso ampliar o debate e trazer esses temas para a sociedade, que 
precisa estar informada e mobilizada: "essa não é uma tarefa fácil quando o assunto é alimentação, porque existem muitas pessoas que alegam que o Estado não pode interferir na escolha dos filhos".

Contrariamente, um depoente da sociedade civil organizada enfatizou que o argumento de que o Estado não tem "tanta força” para regular é pífio, pois delega para outros atores uma atribuição que é dele, a responsabilidade de proteger a criança contra a publicidade abusiva: "as estratégias usadas pela indústria têm como objetivo vender os produtos, aumentar o consumo e fidelizar. Elas operam para lucrar e não têm interesse em promover alimentação saudável, por isso é necessário regular as atividades do setor privado".

Outro depoente da sociedade civil organizada enfatizou que, enquanto não existir uma regulação da publicidade de alimentos, é preciso alertar as pessoas a refletirem sobre o ambiente alimentar em que estão inseridas, pois consideram que tudo o que compram é por decisão própria e não pelos estímulos publicitários. Já o depoente do setor privado comercial argumenta que "em relação a publicidade de produtos e serviços destinados a crianças e adolescentes e anúncios que tangenciam este público, não é preciso criar mais leis, pois o sistema misto de legislação e auto-regulamentação estabelecido pelo CONAR é rigoroso e eficiente".

Quanto aos acordos realizados entre o governo e as indústrias de alimentos para a redução dos teores de sódio, gorduras e açúcares, alguns depoentes da sociedade civil organizada e de instituições governamentais argumentaram que eles não são efetivos para a PAAS e reversão do quadro de obesidade, por considerarem que mesmo que se retire um certo percentual destes ingredientes, os produtos ainda continuam sendo ultraprocessados. Outro argumento é que, ao pactuar a redução desses ingredientes, o Ministério da Saúde chancela esses produtos e sinaliza que podem ser uma opção mais saudável. Esses depoentes enfatizaram que a relação do Estado com o setor privado comercial deveria ser fundamentalmente pautada em ações regulatórias. Por outro lado, atores que também atuam em instituições governamentais defendem os acordos com esse setor e uma relação dialógica e não impositiva.

\section{Discussão}

O Estado foi apontado por todos os depoentes como o principal responsável para enfrentar o problema da obesidade infantil. Todavia, cada segmento conferiu um peso diferente às suas atribuições, tendo em vista que as ideias em disputa são condicionadas pelo contexto institucional em que estão inseridos e pelos interesses em pauta. Observou-se que depoentes da mesma instituição governamental apostaram em estratégias diferentes quanto ao papel do Estado, com posicionamentos divergentes possivelmente devido à sua posição na hierarquia institucional. Os atores que ocupam cargos políticos possuem autonomia relativa, mas sua condição de sujeitos sociais com posicionamentos próprios não deve ser desconsiderada 36.

O lugar na estrutura organizacional da instituição condicionou de modo distinto a fala e o relato dos depoentes. Ou seja, alguns apostam que as medidas mais estratégicas são as que ferem os interesses econômicos do mercado, aqui representado pela indústria de alimentos e bebidas açucaradas e pelo setor publicitário, como a regulação da publicidade de alimentos, a rotulagem frontal e medidas fiscais que impõem a taxação de alimentos ultraprocessados. Já outros vinculados à mesma instituição, mas que se distinguem por ocuparem cargos de direção ou coordenação de áreas técnicas ou programas, defendem formas de enfrentamento da obesidade que não impliquem restrições das atividades do setor privado comercial e que não criem tensionamentos entre o governo e este setor.

As ideias e argumentos do setor privado comercial, identificados tanto na entrevista quanto nos documentos analisados, são pautados na concepção de que cabe aos pais ou ao próprio indivíduo realizar suas escolhas alimentares sem nenhuma interferência do Estado. A superação de um problema que é amplo, complexo e socialmente condicionado, fica reduzida a uma questão de opção individual ou familiar, a uma escolha: "compra quem quer". Esse argumento isenta o setor privado comercial de responsabilidade sobre suas práticas que fomentam o consumo de ultraprocessados e contribuem para as DCNT. Delega a decisão integralmente ao indivíduo, desconsidera o contexto socioambiental que condiciona as práticas alimentares e visa a enfraquecer o poder regulatório do Estado. Essa narrativa é marcada de forma determinante pela crítica a uma ideia de Estado fortemente interventor na vida privada, que corresponderia ao conceito de Estado "babá" 37. 
Por outro lado, ao alegar falta de "civilidade" do consumidor e apostar em medidas de caráter educativo, o setor privado comercial considera que indivíduos carecem de informações, conhecimentos ou habilidades para evitar a obesidade. Com esse discurso, além de se isentar de qualquer responsabilidade, atribui ao consumidor a culpa pelo consumo excessivo dos produtos por ele anunciados e, consequentemente, pela condição de saúde decorrente deste consumo, assumindo uma postura antiética e, no mínimo, contraditória com suas práticas publicitárias e mercadológicas que estimulam o consumo excessivo. Tais ideias indicam contradições internas ao discurso do setor privado comercial, que em um dado momento alega que o Estado não deve interferir nas liberdades individuais e em outro defende que é uma atribuição estatal dizer "o que" e "quanto" a família deve consumir.

A alimentação escolar vem sendo destacada na literatura pelo seu potencial na reversão do excesso de peso e da obesidade, especialmente por ser na infância e adolescência que se estabelecem mais fortemente hábitos alimentares com maiores possibilidades de perdurarem na vida adulta ${ }^{38}$. Nesse sentido, o Programa Nacional de Alimentação Escolar 39 (PNAE) e o Programa Saúde na Escola 40, por serem pautados na intersetorialidade, podem afetar diferentes condicionantes da obesidade infantil, cada um em seu escopo de atuação. O PNAE contribui ainda para a garantia da segurança alimentar e nutricional ao preconizar o uso de alimentos naturais e focalizar a valorização da alimentação adequada, sob os aspectos nutricional, socioambiental e cultural. Seu desenho operacional indica caminhos para a atuação no sistema alimentar ao estabelecer conexões entre produção, comercialização e consumo, apoiar a agricultura familiar, reforçando a concepção de que as questões de alimentação e nutrição devem ser consideradas em uma perspectiva sistêmica e não fragmentada e pontual.

Também em sintonia com a segurança alimentar e nutricional, a Estratégia Intersetorial de Prevenção e Controle da Obesidade 29 prevê ações integradas ao sistema alimentar que valorizem o consumo de alimentos regionais, o aumento da disponibilidade de alimentos saudáveis e a substituição do consumo de ultraprocessados.

No entanto, são as ações regulatórias as que mais tensionam as distintas perspectivas sobre as liberdades individuais quanto às escolhas alimentares 41 , e tais tensões se colocam de forma singular no espaço escolar para onde confluem disputas de ideias quanto às formas de PAAS e prevenção da obesidade. A implementação dos documentos governamentais que estabelecem diretrizes de PAAS nas escolas demanda aprovação dos diferentes segmentos da comunidade escolar. A adesão às recomendações propostas pode, por vezes, produzir resistências dos escolares, dos seus responsáveis e de membros da comunidade escolar 41 .

Cabe ressaltar que é atribuição do Estado regular as práticas mercadológicas e não intervir diretamente nas escolhas individuais, considerando, inclusive, as desigualdades de poder de influência das empresas transnacionais que, por meio da publicidade e de sua ação corporativa, acabam por afetar as escolhas individuais de forma muito mais significativa do que Estado/governos que não empregam o mesmo volume de recursos financeiros em publicidade. A capacidade de influência do Estado ocorre por meio de políticas públicas de apoio, incentivo e proteção (disseminação de informações e ações regulatórias), o que reitera a importância de compras públicas de alimentos para a oferta da alimentação saudável nas escolas.

As ações de educação alimentar e nutricional são as únicas destacadas pelo setor privado comercial para o enfrentamento da obesidade com o argumento de que cabe aos pais decidirem o que os filhos devem comer. Todavia, ações isoladas e descontextualizadas do ambiente obesogênico são insuficientes. A complexidade da mudança na alimentação reitera os limites da educação alimentar e nutricional e confirma a ideia de que o Estado deve regular o setor privado comercial e não os indivíduos. Nesse contexto, apesar de o guia alimentar estar alinhado à PAAS, reconhece os obstáculos para a adoção de suas recomendações, apontando a necessidade tanto de ações e mudanças individuais quanto de políticas públicas e ações regulatórias do Estado que tornem o ambiente mais favorável para as escolhas mais saudáveis 12 .

Embora o guia traga uma abordagem integral da PAAS, com recomendações sobre o consumo de alimentos in natura ou minimamente processados, importa considerar as barreiras enfrentadas em nível individual para reagir à oferta e aos apelos publicitários para o consumo de alimentos não saudáveis dirigidos, sobretudo, ao público infantil. Portanto, o ambiente obesogênico impõe limites para o alcance das suas recomendações. 
O discurso do guia apresenta uma abordagem da alimentação na perspectiva da segurança alimentar e nutricional e, ao recomendar que alimentos ultraprocessados sejam evitados e se dê preferência aos in natura, afeta de forma incisiva os interesses das indústrias de alimentos. Na formulação do documento houve tensões e disputas em torno de interesses divergentes e críticas de setores dessa indústria 42,43 , pois a proposta de classificação dos alimentos evidencia os efeitos nocivos dos ultraprocessados à saúde 7 . Esse processo indica a relevância de determinadas políticas governamentais e da formalização de certas posições e concepções em documentos oficiais do governo.

Para o segmento da sociedade civil organizada, estratégias regulatórias devem ser igualmente adotadas, especialmente para atingir populações mais vulneráveis que nem sempre têm condições de acessar as fontes de informações disponibilizadas. Na visão desses depoentes, o "empoderamento" da população é necessário, todavia, é insuficiente se não coexistirem, no mesmo cenário, políticas que atuem nos ambientes, pois modificações nos hábitos de vida não têm impacto se o ambiente não favorecer que sejam permanentes. Ou seja, é preciso compreender os limites que os pais/responsáveis enfrentam para modificar e influenciar suas escolhas alimentares e de seus filhos em contextos adversos à adoção de práticas saudáveis.

Sem desconsiderar a importância de medidas individualizadas, há que se reconhecer que os argumentos do setor privado comercial indicam os interesses em disputa relativos à possibilidade de operar livremente no mercado. Um exemplo disso pode ser atribuído ao discurso que culpabiliza a mulher, demonstrando sintonia com interesses referentes à oferta de soluções baseadas na praticidade. Portanto, a indústria de alimentos por meio da publicidade de seus produtos argumenta que é possível conciliar o emprego feminino e o cuidado com a alimentação da família.

Empresários do setor publicitário e das grandes indústrias de alimentos possuem forte peso de influência nesse processo ao promoverem seus produtos, ou impedirem ações regulatórias, por meio do financiamento de atividades de pesquisadores e interferências governamentais via parcerias público-privadas $44,45,46$. Os grupos de interesse (público e privado) podem ter maior ou menor poder de influência na formulação de políticas, denotando o grau de intervenção do Estado sobre as relações com o mercado e também a capacidade de concentração de recursos financeiros e políticos que caracterizam as empresas transnacionais que atuam no setor de alimentos, sementes e medicamentos 47 . É uma lógica voltada para interesses de segmentos específicos e não para a construção de bens e espaços públicos. Nesse sentido, os argumentos em defesa dos acordos para a redução de nutrientes críticos atribuem ao setor privado comercial o status de "parceiro", ignorando que ele é parte do problema, e que medidas efetivas para o enfrentamento da obesidade podem ser inconciliáveis com sua lógica e seus interesses 28 .

Embora o texto constitucional defina que o Estado deve assegurar o direito à saúde e à alimentação, assumindo, assim, o papel de legislador e regulador, estratégias que favorecem a oferta, disponibilidade e acesso a alimentos mais saudáveis, propostas pela Agência Nacional de Vigilância Sanitária e pela Câmara Intersetorial de Segurança Alimentar Nutricional em diálogo com a sociedade civil organizada (regulação da publicidade de alimentos e projetos de lei semelhantes), enfrentam dificuldades em sua aprovação e implementação. Os interesses em jogo, que circunscrevem as relações entre os setores público e privado em torno dessa pauta 48,49 , acirram as tensões quando são propostas medidas de natureza regulatória, e o argumento evocado recai sobre a defesa das liberdades de escolha e de expressão.

As diferentes concepções sobre as ações do Estado para o enfrentamento da obesidade infantil demonstram a tensão entre os que defendem mudanças menos "radicais" e incrementais e mudanças transformadoras. Esses se preocupam que as ações incrementais possam cooptar a demanda por mudanças mais significativas 50 como a regulação da publicidade de alimentos, das práticas de marketing e dos teores de sódio, açúcar e gordura da composição de seus produtos.

Assim, a maneira como a obesidade é concebida e os argumentos propostos para a sua prevenção e controle apontam para alternativas diferenciadas de intervenção de acordo com os interesses dos setores. O conjunto de práticas do setor privado comercial, citadas nos documentos e depoimentos, constitui a ação política corporativa deste setor referente às estratégias de disseminação de informações e mensagens favoráveis ao consumo de seus produtos 5 . Coloca o foco na responsabilidade individual, no papel da família e no sedentarismo como fatores condicionantes da obesidade infantil, um tipo de discurso que vem sendo identificado na literatura acadêmica como parte dessas estratégias 6 . 
As questões aqui destacadas reforçam a relevância da análise de disputa de ideias no âmbito das políticas públicas, uma vez que a disseminação de argumentos que justifiquem soluções específicas para os problemas públicos é uma estratégia fortemente utilizada no curso da ação política com o objetivo de garantir que determinados interesses sejam atendidos. As ações e os programas são também um discurso em torno de "certas" concepções adotadas, indicam as contradições internas ao governo e ao próprio Estado que é uma esfera de disputa por recursos públicos. As desigualdades históricas do país tornam essa análise ainda mais relevante.

Outra disputa de ideias refere-se aos que defendem mudança nas práticas alimentares em vez do uso de medicamentos e cirurgia bariátrica, que inclusive já vem sendo preconizada para adolescentes 16 e pode estar associada a interesses específicos do setor privado comercial em produzir suplementos e medicamentos. Contudo, essa é também a base argumentativa de profissionais de saúde que defendem a suplementação medicamentosa, seja porque estão atrelados à indústria, seja porque acreditam que os déficits de desenvolvimento infantil são decorrentes de uma má alimentação e que a mudança de práticas alimentares é muito difícil.

A análise das concepções sobre a obesidade infantil e o papel do Estado sugere que os embates são moldados por interesses divergentes, mas os conflitos, especialmente entre a sociedade civil organizada e o setor privado comercial, podem indicar que algumas Instituições do Estado atuam como um pêndulo que ora se inclina para beneficiar os interesses do mercado, ora se inclina na direção da sociedade. Isso se deve à própria constituição do Estado, que é altamente permeável aos interesses do mercado 51, mas que nos últimos anos passou a incluir a participação da sociedade civil nos processos decisórios por meio de distintos dispositivos, ainda com certa desproporcionalidade quanto ao capital político de cada segmento. Desse modo, as ações estatais atendem a múltiplos objetivos e a interesses por vezes contraditórios.

Quanto à publicidade de alimentos para o público infantil, os poucos dispositivos legais existentes não são cumpridos integralmente pelas empresas, pois alegam liberdade de expressão comercial. Contudo, sabe-se que o consumo dos alimentos anunciados nos diferentes meios contribui para a obesidade infantil. Além disso, trata-se de uma relação assimétrica, considerando-se a inexperiência da criança e seus limites de julgamento.

A captura do papel regulador do Estado por grupos privados pode tornar a abordagem das relações entre setores público e privado individualizada, em vez de institucionalizada 52 . A comissão sobre obesidade da revista Lancet reconhece que o caminho para avançar é intrínseco à complexidade do problema, e considera que a "inércia política para descrever os efeitos combinados da inadequada liderança e governança política" explica a ineficiência em aprovar políticas que respondam de forma global ao problema da obesidade 53 (p. 791). Alguns segmentos da sociedade civil organizada têm apostado em estratégias diversificadas para informar e mobilizar a sociedade para essa pauta política.

\section{Considerações finais}

As concepções sobre obesidade infantil, bem como as ações propostas para seu enfrentamento, estão relacionadas com as ideias e os interesses em torno dos tipos de intervenção que são possíveis; do papel que os governos desempenham; do âmbito de atuação governamental; e das atribuições dos diferentes setores e instituições envolvidos. Portanto, as ações regulatórias que tensionam o setor privado comercial e podem incidir diretamente no lucro das empresas envolvem disputas em torno de atribuições estatais que podem afetar sua margem de lucro.

As ideias em disputa sobre os fatores condicionantes da obesidade, sobre a forma como se explica o problema e sobre quais as ações devem ser adotadas pelo Estado indicam a dinâmica de interesses e influências que envolvem a questão alimentar e nutricional em torno do Estado. As estratégias governamentais de apoio, incentivo e proteção são igualmente importantes, mas sua operacionalização impõe desafios políticos e de gestão que são distintos. As ações regulatórias que se propõem a criar diretrizes e/ou restrições para a atuação do setor privado comercial são as que mais provocam o debate sobre os limites de atuação do Estado na regulação das atividades comerciais e/ou de espaços institucionais. Essas ações objetivam proteger a população contra práticas não saudáveis e abusivas, 
no entanto, são capitaneadas no discurso do setor privado como ações que cerceiam a liberdade dos indivíduos, ainda que sejam voltadas para regular as práticas deste setor.

Os argumentos contrários à atribuição regulatória do Estado são pautados nos condicionantes "individuais" da obesidade o que a princípio parece ser um contrassenso, pois são as práticas institucionais do setor privado comercial que são objeto de regulação e não o comportamento dos indivíduos. Esse tipo de argumento é parte da ação política corporativa, pois omite os conflitos de interesses com o setor privado comercial, que vêm contribuindo para retardar a redução da prevalência da obesidade em diferentes países.

\section{Colaboradores}

P. Henriques contribuiu com a concepção e desenho do estudo, coleta e interpretação dos dados, redação do manuscrito e aprovação da versão final. L. Burlandy contribuiu com a concepção e desenho do estudo, interpretação dos dados, redação do manuscrito e aprovação da versão final. P. C. Dias contribuiu com a interpretação dos dados, redação do manuscrito e aprovação da versão final. G. O’Dwyer contribuiu com a concepção do estudo, revisão crítica do conteúdo intelectual e aprovação da versão final.

\section{Informações adicionais}

ORCID: Patrícia Henriques (0000-0001-81540962); Luciene Burlandy (0000-0003-0875-6374); Patricia Camacho Dias (0000-0002-0674-8832); Gisele O’Dwyer (0000-0003-0222-1205).

\section{Agradecimentos}

Agradecemos a todos os depoentes que participaram do estudo.

\section{Referências}

1. Departamento de Vigilância de Doenças e Agravos não Transmissíveis e Promoção da Saúde Secretaria de Vigilância em Saúde, Ministério da Saúde. Vigitel Brasil 2017: vigilância de fatores de risco e proteção para doenças crônicas por inquérito telefônico. Estimativas sobre frequência e distribuição sociodemográfica de fatores de risco e proteção para doenças crônicas nas capitais dos 26 estados brasileiros e no Distrito Federal em 2017. Brasília: Ministério da Saúde; 2018.

2. Instituto Brasileiro de Geografia e Estatística. Pesquisa de Orçamentos Familiares 20082009: antropometria e estado nutricional de crianças, adolescentes e adultos no Brasil. Rio de Janeiro: Instituto Brasileiro de Geografia e Estatística; 2010.

3. Instituto Brasileiro de Geografia e Estatística. Pesquisa de Orçamentos Familiares 20082009: análise do consumo alimentar pessoal no Brasil. Rio de Janeiro: Instituto Brasileiro de Geografia e Estatística; 2011.

4. World Health Organization. Guideline: sugars intake for adults and children. Geneva: World Health Organization; 2015.

5. Gomes FS. Conflitos de interesse em alimentação e nutrição. Cad Saúde Pública 2015; 31:2039-46.

6. Mialon M, Swinburn B, Sacks G. A proposed approach to systematically identify and monitor the corporate political activity of the food industry with respect to public health using publicly available information. Obes Rev 2015; 16:519-30.

7. Mialon M, Sêrodio P, Scagliusia FB. Criticism of the NOVA classification: who are the protagonists? World Nutrition 2018; 9:176-240.

8. Henriques P, O'Dwyer G, Dias PC, Barbosa RMS, Burlandy L. Políticas de Saúde e de Segurança Alimentar e Nutricional: desafios para o controle da obesidade infantil. Ciênc Saúde Colet 2018; 23:4143-52. 
9. Brasil. Lei no 11.346, de 15 de setembro de 2006. Cria o Sistema Nacional de Segurança Alimentar e Nutricional com vista a assegurar o direito humano à alimentação adequada e dá outras providências. Brasília, 2006. Diário Oficial da União 2006; 18 set.

10. Ministério da Saúde. Secretaria de Atenção à Saúde. Departamento de Atenção Básica. Política Nacional de Alimentação e Nutrição. Brasília: Ministério da Saúde; 2012.

11. Ministério da Saúde. Política Nacional de Promoção da Saúde. Brasília: Ministério da Saúde; 2014.

12. Departamento de Atenção Básica, Secretaria de Atenção à Saúde, Ministério da Saúde. Guia alimentar para a população brasileira. Brasília: Ministério da Saúde; 2014.

13. Secretaria de Atenção Primária à Saúde, Ministério da Saúde. Guia alimentar para crianças menores de dois anos. Brasília: Ministério da Saúde; 2019.

14. Secretaria Nacional de Segurança Alimentar e Nutricional, Ministério do Desenvolvimento Social e Combate à Fome. Marco de referência de educação alimentar e nutricional para as políticas públicas. Brasília: Ministério do Desenvolvimento Social e Combate à Fome; 2012.

15. Henriques P, Dias PC, Burlandy L. A regulamentação da propaganda de alimentos no Brasil: convergências e conflitos de interesses. Cad Saúde Pública 2014; 30:1219-28.

16. Dias PC, Henriques P, Anjos LA, Burlandy L. Obesidade e políticas públicas: concepções e estratégias adotadas pelo governo brasileiro. Cad Saúde Pública 2017; 33:e00006016.

17. Nascimento PU, Lacerda TBCH, Nascimento GD. A intervenção do estado no poder familiar. Múltiplos Acessos 2016; 1:99-121.

18. Pinheiro ARO, Carvalho DBB. Estado e Mercado: adversários ou aliados no processo de implementação da Política Nacional de Alimentação e Nutrição? Elementos para um debate sobre medidas de regulamentação. Saúde Soc 2008 ; 17:170-83.

19. Holfing EM. Estado e políticas (públicas) sociais. Cadernos Cedes 2001; (55):30-42.

20. Lipson L. Os grandes problemas da ciência política. Uma introdução à Ciência Política. Rio de Janeiro: Zahar Editores, 1976.

21. Hall PA. The role of interests, institutions and ideas in the comparative political economy of industrialized nations. In: Lichbach MI, Zuckerman AS, editors. Comparative politics: rationality, culture and structure. Cambridge: University Press; 1997. p. 174-207.

22. Surel Y. Idées, intérêts, institutions dans l'analyse des politiques publiques. Pouvoirs 1998; 87:161-78.

23. Niederle PA, Grisa C. Ideias e valores: a análise da ação pública a partir das interfaces entre a abordagem cognitiva e a economia das convenções. Política \& Sociedade 2013; 23:97136.
24. Robbins R, Niederdeppe J, Lundell H, Meyerson J. Views of city, county and state policy makers about childhood obesity in New York State, 2010-2011. Prev Chronic Dis 2013; 10:E195.

25. Brasil. Portaria Interministerial no $1.010,8$ de maio de 2006. Institui diretrizes para promoção da alimentação saudável nas escolas de educação infantil, fundamental e nível médio das redes públicas e privadas, em âmbito nacional. Brasília: Diário Oficial da União 2006; 9 mai.

26. Departamento de Atenção Básica, Ministério da Saúde. Dez passos para uma alimentação saudável. Brasília: Ministério da Saúde; 2010.

27. Departamento de Atenção Básica, Ministério da Saúde. Manual das cantinas escolares saudáveis: promovendo a alimentação saudável. Brasília: Ministério da Saúde; 2010.

28. Ministério da Saúde. Plano de ações estratégicas para o enfrentamento das doenças crônicas não transmissíveis no Brasil 2011-2022. Brasília: Ministério da Saúde; 2011.

29. Câmara Interministerial de Segurança Alimentar e Nutricional. Estratégia intersetorial de prevenção e controle da obesidade: recomendações para estados e municípios. Brasília: Câmara Interministerial de Segurança Alimentar e Nutricional; 2014.

30. Conselho Nacional de Segurança Alimentar e Nutricional. Legislação básica do Sistema Nacional de Segurança Alimentar e Nutricional. Brasília: Presidência da República; 2017.

31. Conselho Nacional de Autorregulamentação Publicitária. O fator publicidade de alimentos e refrigerantes e sua relação com a obesidade. Produtos seguros, alimentação balanceada, atividade física e informação: a dieta do CONAR. São Paulo: Conselho Nacional de Autorregulamentação Publicitária; 2010.

32. Conselho Nacional de Autorregulamentação Publicitária. As normas éticas e a ação do CONAR na publicidade de produtos e serviços destinados a crianças e adolescentes. São Paulo: Conselho Nacional de Autorregulamentação Publicitária; 2015.

33. Brasil. Lei no 8.069, de 13 de julho de 1990. Dispõe sobre o Estatuto da Criança e do Adolescente e dá outras providências. Diário Oficial da União 1990; 16 jul.

34. Brasil. Lei no 8.078 , de 11 de setembro de 1990. Código de Defesa do Consumidor. Dispõe sobre a Proteção do Consumidor e dá outras Providências. Diário Oficial da União 1990; 12 set.

35. Conselho Nacional dos Direitos da Criança e do Adolescente. Resolução no 163, de 13 de março de 2014. Dispõe sobre a abusividade do direcionamento de publicidade e de comunicação mercadológica à criança e ao adolescente. Diário Oficial da União 2014; 4 abr. 
36. Ianoni M. Autonomia do Estado e desenvolvimento no capitalismo democrático. Revista de Economia Política 2013; 33:577-98.

37. Harsanyi D. Crítica ao estado babá. Rio de Janeiro: Litteris; 2011.

38. Teo CRPA, Monteiro CA. Marco legal do Programa Nacional de Alimentação Escolar: uma releitura para alinhar propósitos e práticas na aquisição de alimentos. Rev Nutr 2012; 25:657-68.

39. Brasil. Lei no 11.947 , de 16 de junho de 2009. Dispõe sobre o atendimento da alimentação escolar e do Programa Dinheiro Direto na Escola aos alunos da educação básica; altera as Leis nos 10.880, de 9 de junho de 2004, 11.273, de 6 de fevereiro de 2006, 11.507, de 20 de julho de 2007; revoga dispositivos da Medida Provisória no 2.178-36, de 24 de agosto de 2001, e a Lei no 8.913, de 12 de julho de 1994; e dá outras providências. Diário Oficial da União 2009; 17 jun.

40. Brasil. Decreto no 6.286, de 5 de dezembro de 2007. Institui o Programa Saúde na Escola e dá outras providências. Diário Oficial da União 2007; 6 dez.

41. Dutra RCA. Consumo alimentar infantil: quando a criança é convertida em sujeito. Sociedade e Estado 2015; 30:451-69.

42. Madi, L, Rego RA. Brasil processed Food 2020: um projeto em defesa da industrialização de alimentos. Brazilian J Food Technol 2015; 18:337-9.

43. Gibney MJ, Forde CG, Mullally D, Gibney ER. Ultraprocessed foods in human health: a critical appraisal. Amer J Clin Nutrition 2017; 106:717-24.

44. Canella DS, Martins APB, Hugo FR, Silva HFR, Passanha A, Lourenço BH. Food and beverage industries participation in health scientific events: considerations on conflicts of interest. Rev Panam Salud Pública 2015; 38:339-343.
45. Burlandy L, Alexandre VP, Gomes FS, Castro IRR, Dias PC, Henriques P. et al. Políticas de promoção da saúde e potenciais conflitos de interesses que envolvem o setor privado comercial. Ciênc Saúde Colet 2016; 21:1809-18.

46. UK Health Forum. Public health and the food and drinks industry: the governance and ethics of interaction. Lessons from research, policy and practice. London: UK Health Forum; 2018.

47. Moodie R, Stuckler D, Monteiro C, Sheron N, Neal B, Thamarangsi T. Profits and pandemics: prevention of harmful effects of tobacco, alcohol, and ultra-processed food and drink industries. Lancet 2013; 381:670-9.

48. Baird MF. O lobby na regulação da publicidade de alimentos da Agência Nacional de Vigilância Sanitária. Revista de Sociologia Política 2016; 24:67-91.

49. Magalhaes R. Regulação de alimentos no Brasil. Revista de Direito Sanitário 2017; 17:11333.

50. Freudenberg N. Reducing inequalities in child obesity in developed nations: what do we know? What can we do? Revista Portuguesa de Saúde Pública 2013; 31:115-22.

51. Nunes AJA. As duas últimas máscaras do estado capitalista. Pensar 2011; 16:409-76.

52. Storeng KT, Palmer J. When ethics and politics collide in donor-funded global health research. Lancet 2019; 394:184-6.

54. Swinburn BA, Kraak VI, Allender S, Atkins VJ, Baker PI, Bogard JR, et al. The global syndemic of obesity, undernutrition, and climate change: the Lancet Comission. Lancet 2019; 393:791846. 


\section{Abstract}

The study analyzed competing ideas on the State's roles in the prevention and control of childhood obesity in Brazil, with cognitive analysis of public policies as the frame of reference. The study included document analysis and semi-structured interviews with 20 individuals from government, organized civil society, and the commercial private sector. The State was viewed as the main party responsible for dealing with childhood obesity, but the definitions of its roles varied according to the narratives on the factors that condition obesity and the proposed solutions. Members of the commercial private sector criticized the regulatory State in the name of parents' freedom of choice. Civil society representatives and part of the government defended regulatory measures, which they considered essential. They contended that agreements between government and the food industry to reduce unhealthy ingredients are ineffective. However, some government representatives defended such agreements. These tensions and contradictions were also expressed in the policy documents acknowledging that practices by the commercial private sector favor obesity, even while considering the private sector a partner in this process. The arguments against the regulatory State were based on individual factors conditioning obesity, but the object of regulation is institutional practices by the commercial private sector, not individual behaviors. However, this kind of argument is part of corporate policy activity, since it overlooks the conflicts of interests that have contributed to delaying the reduction in obesity prevalence.

Child Obesity; Nutrition Programs and Policies;

Obesity Management; State

\section{Resumen}

El estudio analizó las ideas en disputa en torno a las atribuciones del Estado en cuanto a la prevención y control de la obesidad infantil en Brasil, basándose en el marco referencial del análisis cognitivo de políticas públicas. Se realizó un análisis documental, al igual que una entrevista semiestructurada con 20 participantes, relacionados con diferentes esferas del Estado/Gobierno, sociedad civil organizada, así como del sector privado comercial. El Estado fue considerado el principal responsable del combate a la obesidad infantil, pero las concepciones sobre sus atribuciones variaron de acuerdo con las narraciones sobre los condicionantes de la obesidad y las soluciones presentadas. El sector privado comercial critica al Estado regulador, en nombre de la libertad de decisión de los padres. Los representantes de la sociedad civil y del gobierno valoran las acciones regulatorias y reconocen que son fundamentales. Consideran que los acuerdos para la reducción de ingredientes, realizados entre el gobierno y la industria alimentaria, no son efectivos. Sin embargo, algunos representantes del gobierno los defienden. Estas tensiones y contradicciones también se expresan en los documentos de politicas que reconocen que las prácticas del sector privado comercial favorecen la obesidad, pero lo consideran como un aliado. Los argumentos contrarios al Estado regulador se encuentran pautados en los condicionantes individuales de la obesidad, no obstante, las prácticas institucionales del sector privado comercial son las que son objeto de regulación, y no el comportamiento de los individuos. Sin embargo, este tipo de argumento forma parte de la acción política corporativa, puesto que omite los conflictos de intereses que han contribuido a retrasar la reducción de la prevalencia de la obesidad.

Obesidad Pediátrica; Programas y Políticas de Nutrición y Alimentación; Manejo de la Obesidad; Estado
Recebido em 29/Jan/2020

Versão final reapresentada 29/Abr/2020

Aprovado em 06/Mai/2020 